\title{
Protopine Protects Mice against LPS-Induced Acute Kidney Injury by Inhibiting Apoptosis and Inflammation via the TLR4 Signaling Pathway
}

\author{
Beibei Zhang ${ }^{1,2}$, Mengnan Zeng ${ }^{1,2}$, Meng Li ${ }^{1,2}$, Yuxuan Kan ${ }^{1,2}$, Benke $\mathrm{Li}^{1,2}$, Ruiqi Xu ${ }^{1,2}$, \\ Yuanyuan $\mathrm{Wu}^{1,2}$, Shengchao Wang ${ }^{1,2}$, Xiaoke Zheng ${ }^{1,2, *}$ and Weisheng Feng ${ }^{1,2, *}$ \\ 1 College of Pharmacy, Henan University of Chinese Medicine, Zhengzhou 450046, \\ China; zhangs9426@163.com (B.Z.); 17320138484@163.com (M.Z.); limeng31716@163.com (M.L.); \\ kanyx0827@163.com (Y.K.); libk2017@163.com (B.L.); xuruiqi9647@163.com (R.X.); \\ WYY96191711@163.com (Y.W.); wangsc1204@163.com (S.W.) \\ 2 Collaborative Innovation Center for Respiratory Disease Diagnosis and Treatment \& Chinese Medicine \\ Development of Henan Province, Zhengzhou 450046, China \\ * Correspondence: zhengxk.2006@163.com (X.Z.); fwsh@hactcm.edu.cn (W.F.); Tel.: +86-371-60190296 (W.F.)
}

Received: 12 September 2019; Accepted: 14 October 2019; Published: 19 December 2019

\begin{abstract}
Corydalis humosa Migo is a traditional Chinese medicine that clears away damp heat, relieves sore. Protopine (PRO) is an alkaloid component isolated from C. humosa Migo. However, the role of protopine in acute kidney injury (AKI) has not yet been reported. This study aims to investigate the effect and mechanism of protopine isolated from C. humosa Migo on lipopolysaccharide (LPS)-induced AKI in mice. Inflammation accumulation was assessed by small animal living imaging. The blood urea nitrogen (BUN), and serum creatinine (Scr) were measured to assess the effects of protopine on renal function in LPS-induced AKI. The levels of tumor necrosis factor (TNF), interleukin-2 (IL-2), interferon- $\gamma$ (IFN- $\gamma$ ), and (interleukin-10) IL-10 in serum were detected by cytometric bead array. Flow cytometry was used to detect the levels of reactive oxygen species (ROS) in primary kidney cells. The proportions of granulocytes, neutrophils, and macrophages in peripheral blood were examined to evaluate the effect of protopine on immune cells in mice with AKI. Toll-like receptor (TLR4) and apoptotic signaling pathway were detected by Western blot analysis. The results showed that protopine markedly improved the renal function, relieve inflammation, reversed inflammatory cytokines, transformed apoptosis markers, and regulated the TLR4 signaling pathway in mice with AKI induced by LPS. The protopine isolated from C. humosa Migo protected mice against LPS-induced AKI by inhibiting apoptosis and inflammation via the TLR4 signaling pathway, thus providing a molecular basis for a novel medical treatment of AKI.
\end{abstract}

Keywords: protopine; acute kidney injury; apoptosis; inflammation; TLR4 signaling pathway

\section{Introduction}

The essence of sepsis is systemic inflammatory reactions. Multiple inflammatory mediators and enzymes participate in organism damage; however, the kidney is the most sensitive organ in sepsis infection [1]. Acute kidney injury (AKI) is a clinical syndrome caused by a variety of pathogens, leading to morbidity and mortality in patients [2]. The pathogenesis is complicated, including pro-inflammatory cytokines, ROS, and cell apoptosis [3-5]. Lipopolysaccharide (LPS)-induced sepsis remains the leading cause of AKI. One of the mechanisms of sepsis-induced AKI involves the release of bacterial endotoxins into the circulation, which activate interconnected inflammatory cascades in the kidney, ultimately leading to renal injury [6]. Because of the early excessive inflammatory response, T cells, B cells, and dendritic cells (DC) are severely depleted, 
and the body's immune system is in a paralyzed state. An increasing number of studies suggest that immunosuppression in the late stage of sepsis is the main cause of the high mortality rate in patients with sepsis [7].

Pro-inflammatory cytokines have been shown to exacerbate ROS generation [8], which can activate several intracellular signaling pathways including the one that involves the transcription factor NF-KB [9]. ROS is a highly biologically active oxygen molecule, and increased levels of ROS can induce apoptosis [10]. During the development of AKI, a large number of renal tubular epithelial cells in the nephrons are apoptotic, leading to cell necrosis. AKI could lead to the destruction of the mitochondrial outer membrane, resulting in high expression of TNF- $\alpha$, Bax, and caspase that induce apoptosis. In addition, the expression of an important anti-apoptotic gene $B c l-2$ decreases, inducing apoptosis [11]. Studies have found that LPS can promote the expression of TLR4 and NF- KB apoptosis-related receptors, inducing systemic inflammatory response and causing apoptosis and multiple organ damage [12]. Moreover, TLR4 activation in primary human lung cancer cells increased their ROS levels [13].

C. humosa Migo is from the Papaveraceae family, and the tuber of C. humosa Migo is used in traditional Chinese medicine, which could clear away damp heat, relieve sore, promote blood circulation, and relieve pain. Studies have shown that the compositions of $C$. humosa Migo tuber extract are mostly alkaloids, such as $l$-tetrahydrocoptisine, hydroprotopine, $d l$-tetrahydrocoptisine, berberine, and $d l$-tetrahydroberberine etc. $[14,15]$. In our study, protopine is an alkaloid component isolated from C. humosa Migo humosa Migo and studies have shown that protopine has many demonstrated biological activities, such as anti-inflammatory [16], anti-parasitic [17], antimicrobial [18], and hepatoprotective effects, in animal models [19]. However, the role of protopine in AKI remains unknown. This study was performed to investigate the effects of protopine on LPS-induced AKI and explore the underlying mechanisms.

\section{Results}

\subsection{Compound Identification and Structural Elucidation}

Compound LDD-16 was obtained as white spheroidal crystals soluble in chloroform. The ferric chloride-potassium ferricyanide reagent does not develop color and the color reaction of the modified iodinated potassium reagent is positive, suggesting that it is an alkaloid component. For the ${ }^{1} \mathrm{H}-\mathrm{NMR}$ spectrum of 1 (Table 1), eight hydrogen proton signal peaks were observed in the aromatic region; $\delta$ $6.94(1 \mathrm{H}, \mathrm{s}, \mathrm{H}-1)$ and $6.79(1 \mathrm{H}, \mathrm{s}, \mathrm{H}-4)$ denoted a set of para-hydrogen signals on the benzene ring; $\delta 6.70(1 \mathrm{H}, \mathrm{d}, J=8.0 \mathrm{~Hz}, \mathrm{H}-11)$ and $6.66(1 \mathrm{H}, \mathrm{d}, J=8.0 \mathrm{~Hz}, \mathrm{H}-12)$ denoted a set of ortho-hydrogen signals on the benzene ring; $\delta 5.98(2 \mathrm{H}, \mathrm{s})$ and $5.95(2 \mathrm{H}, \mathrm{s})$ denoted the characteristic signal peak of two methylenedioxy groups. In addition to the hydrogen signal on the $N$-methyl group at $\delta 1.81$, eight hydrogen proton signal peaks were observed in the high-field region. The ${ }^{13} \mathrm{C}-\mathrm{NMR}$ spectrum displayed a total of 20 carbons. Besides a carbonyl group at $\delta 194.6$, two methylenedioxy groups were found at $\delta 100.6$ and $\delta 101.0$. Further, 12 carbon signals were observed, suggesting the presence of 2 benzene rings; $\delta 41.0$ was a characteristic signal peak of the methyl group. In the $1 \mathrm{H}$ detected heteronuclear multiple bond correlation (HMBC) spectrum, 86.79 had a cross peak with 830.4 (C-5) and $\delta 6.66$ had a cross peak with $\delta 46.6$ (C-13), suggesting that H-4 was adjacent to $\mathrm{C}-5$ and $\mathrm{H}-12$ was adjacent to C-13; 86.94 had a cross peak with 8194.6 (C-14), suggesting that H-1 was adjacent to C-14; 85.95 had a cross peak with $\delta 145.7$ (C-9) and $\delta 145.1$ (C-10), suggesting that methylenedioxy was attached to C-9 and C-10; $\delta 5.98$ had a cross peak with $\delta 147.2$ (C-2) and 145.2 (C-3), suggesting that methylenedioxy was attached to $C-2$ and $C-3 ; \delta 1.81$ had a cross peak with 850.6 (C-8) and 57.3 (C-6), suggesting that both C- 6 and C- 8 were connected to N. Based on the aforementioned analysis and literature review, the structure of the compound LDD-16 was determined to be protopine, which is shown in Figure 1. 
Table 1. NMR data for compound LDD-16 in DMSO- $d_{6}$.

\begin{tabular}{ccc}
\hline NO. & $\delta_{\mathbf{H}}$ & $\delta_{\mathbf{C}}$ \\
\hline $1 \mathrm{a}$ & $6.94(1 \mathrm{H}, \mathrm{s})$ & 132.6 \\
1 & & 107.2 \\
2 & & 147.2 \\
3 & $6.79(1 \mathrm{H}, \mathrm{s})$ & 145.2 \\
4 & & 106.2 \\
$4 \mathrm{a}$ & & 135.9 \\
5 & & 30.4 \\
6 & & 57.3 \\
8 & & 50.6 \\
$8 \mathrm{a}$ & & 118.2 \\
9 & & 145.7 \\
10 & & 145.1 \\
11 & & 110.3 \\
12 & & 124.9 \\
$12 \mathrm{a}$ & & 129.5 \\
13 & $6.66(1 \mathrm{H}, \mathrm{d}, \mathrm{d}, \mathrm{J}=8.0 \mathrm{~Hz})$ & 46.0 \\
14 & & 194.6 \\
$-\mathrm{OCH} \mathrm{H}_{2} \mathrm{O}-$ & & 100.6 \\
$\mathrm{~N}-\mathrm{CH}_{3}$ & $5.95(2 \mathrm{H}, \mathrm{s})$ & 101.0 \\
\hline
\end{tabular}

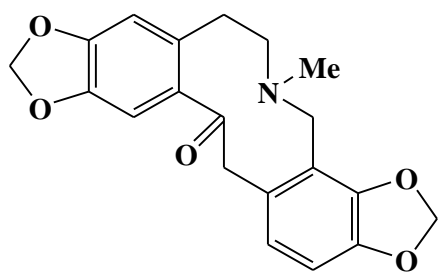

Figure 1. Structure of compound LDD-16.

\subsection{Effects of Protopine on the Renal Function in Mice with LPS-Induced AKI}

As shown in Figure 2, no significant pathological changes were found in the kidneys of control mice. In contrast, obvious renal pathological damage was observed in mice with LPS-induced AKI, including glomerular atrophy, large number of red blood cells, tubular cell vacuolation, tubular dilation and distortion, tubular cell necrosis, and nuclear loss. However, these LPS-induced pathological changes were significantly attenuated by PRO dose-dependently. In addition, the levels of BUN and Scr in mice treated with LPS increased significantly, which were reduced by PRO. 
A

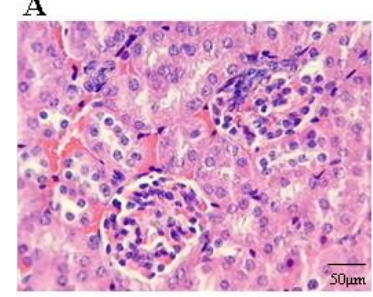

$\mathrm{CON}$

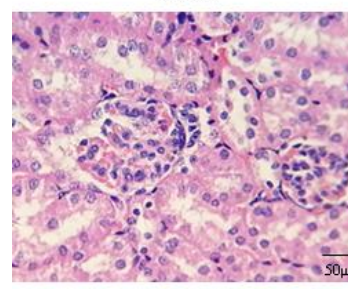

MPRO

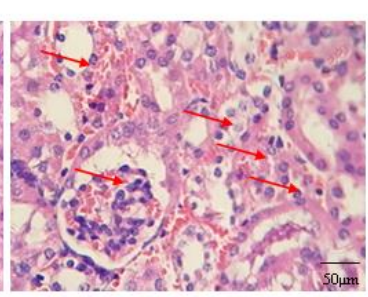

LPS

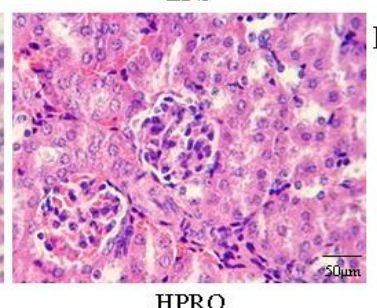

HPRO

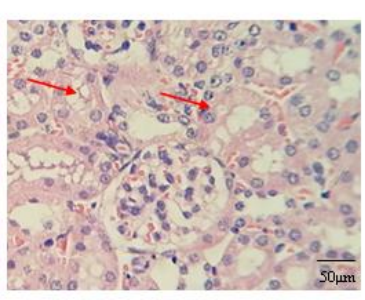

LPRO

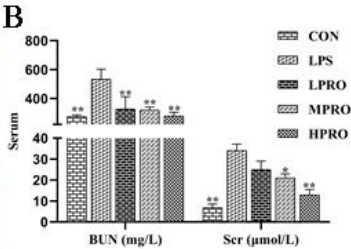

Figure 2. Effects of protopine on the renal function in mice with LPS-induced acute kidney injury (AKI). (A) Representative histopathological images for the H\&E staining of formalin-fixed kidney tissues from each group (400× magnification); scale bar $50 \mu \mathrm{m}$. (B) Effects of protopine on Scr and BUN in mice with LPS-induced AKI ( $n=8$ mice per group). ${ }^{*} p<0.05,{ }^{* *} p<0.01$ compared with the LPS group. (LPRO: low-dose protopine; MPRO: medium-dose protopine; HPRO: high-dose protopine; LPS: lipopolysaccharide; AKI: acute kidney injury; Scr: serum creatinine; BUN: blood urea nitrogen; H\&E: hematoxylin and eosin).

\subsection{Effects of Protopine on Apoptosis in Mice with LPS-Induced AKI}

The effects of protopine on oxidative stress in mice with AKI were investigated by measuring the levels of ROS in primary renal cells using FCM. As shown in Figure 3, the results revealed that the levels of ROS increased in mice with LPS-induced AKI, which could be reduced by protopine.

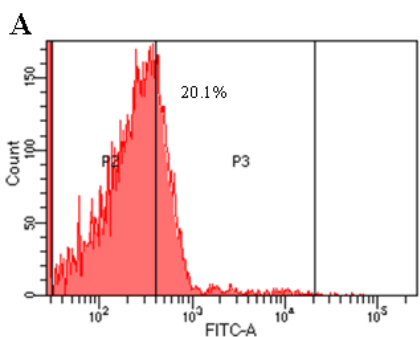

$\mathrm{CON}$

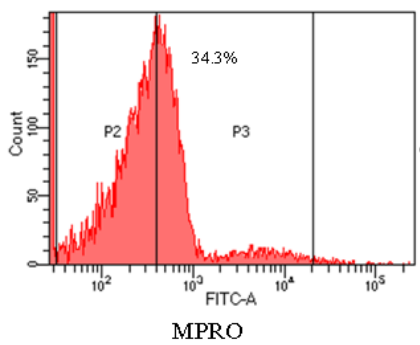

MPRO

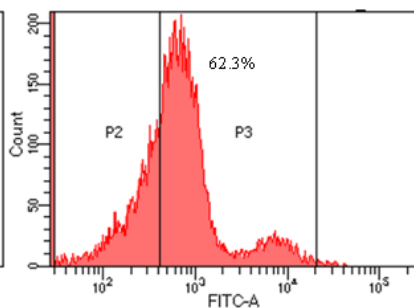

LPS

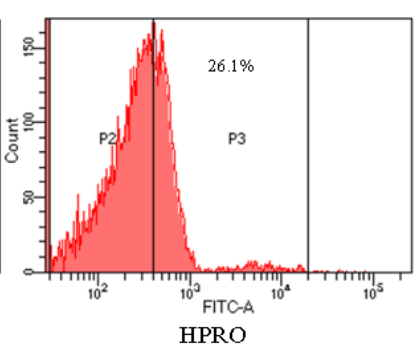

Figure 3. Cont.
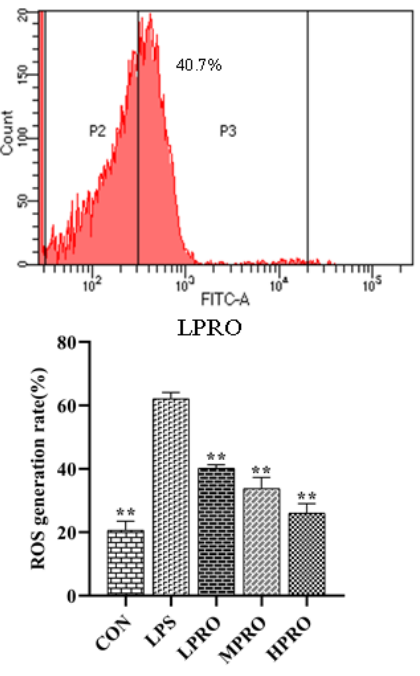
B
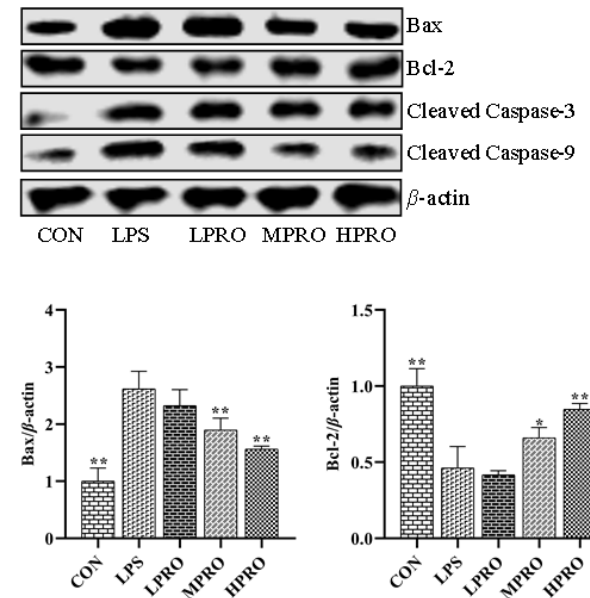
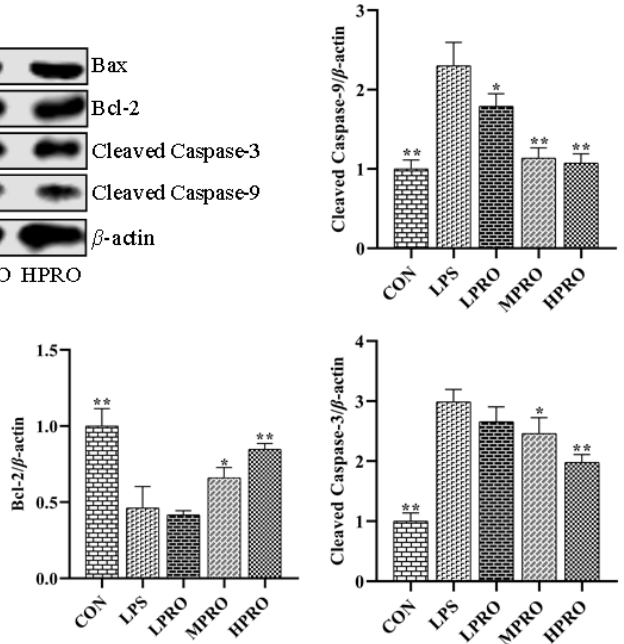

Figure 3. Effects of protopine on cell apoptosis in mice with LPS-induced AKI ( $n=8$ mice per group). (A) Effects of protopine on oxidative stress in mice with LPS-induced AKI. (B) Effects of protopine on apoptosis marker proteins in mice with LPS-induced AKI. ${ }^{*} p<0.05,{ }^{* *} p<0.01$ compared with the LPS group. (LPRO: low-dose protopine; MPRO: medium-dose protopine; HPRO: high-dose protopine; LPS: lipopolysaccharide; AKI: acute kidney injury; ROS: reactive oxygen species; FCM: flow cytometry; Bax: associated X protein; Bcl-2: B-cell lymphoma 2).

Increased levels of ROS in the cells could induce apoptosis. The levels of apoptosis marker proteins were determined by Western blot analysis to assess the effect of protopine on LPS-induced apoptosis. As shown in Figure 3, the results demonstrated the downregulation of pro-apoptotic protein Bax, apoptotic promoter caspase-3, and apoptosis executor caspase- 9 and the upregulation of Bcl-2 by protopine.

\subsection{Effects of Protopine on Inflammation in Mice with LPS-Induced AKI}

To assess the effect of protopine on inflammatory response in vivo, inflammation accumulation and some representative inflammatory cytokines were determined by small animal imaging and CBA, respectively. As shown in Figure 4, there is more severe inflammation accumulation in LPS-induced mice compared with control mice, which could be alleviated by protopine. In addition, the levels of IFN- $\gamma$, TNF, and IL-2 were significantly increased, which could be reversed by protopine effectively. The level of IL-10 significantly increased in the serum of mice with LPS-induced AKI. However, the level of IL-10 further significantly increased after treatment with protopine.
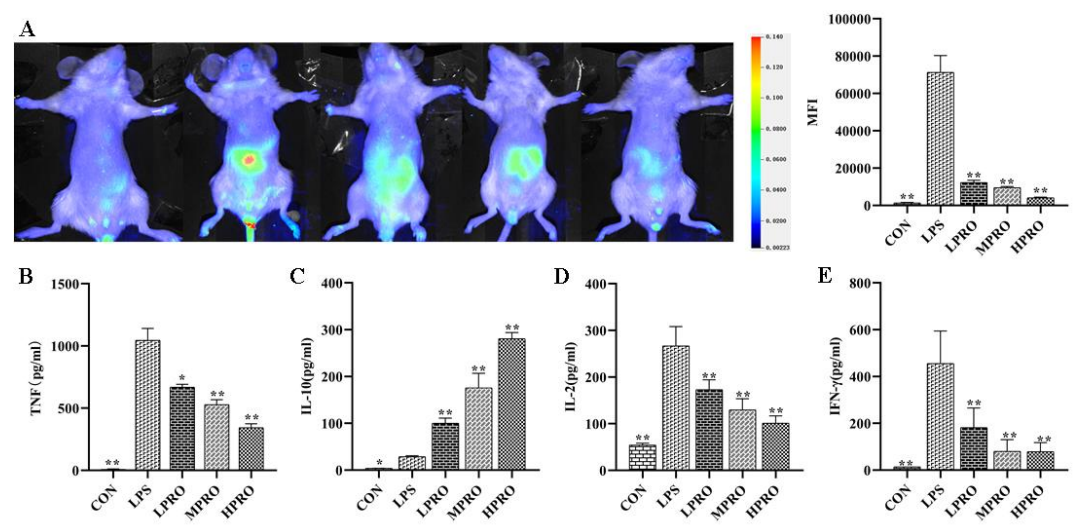

Figure 4. Cont. 

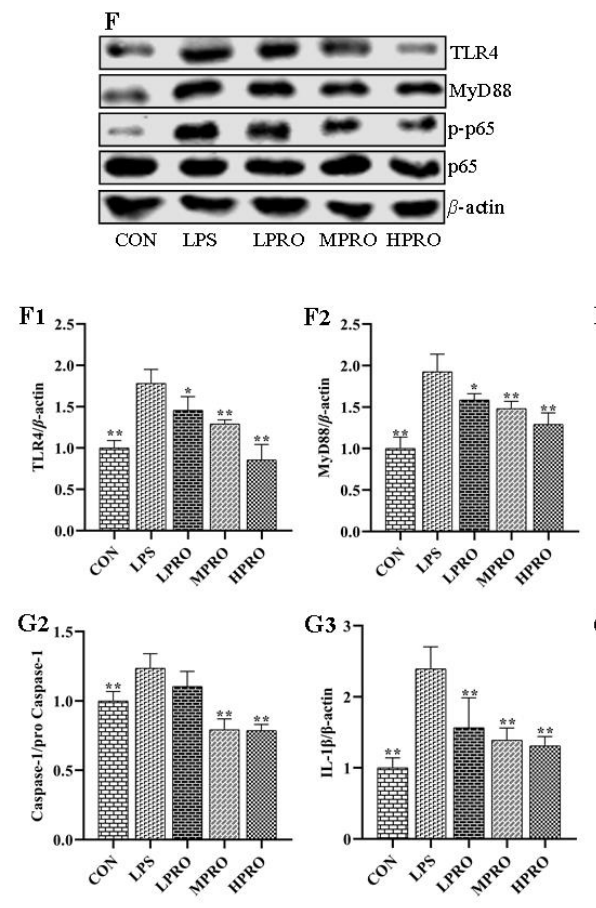
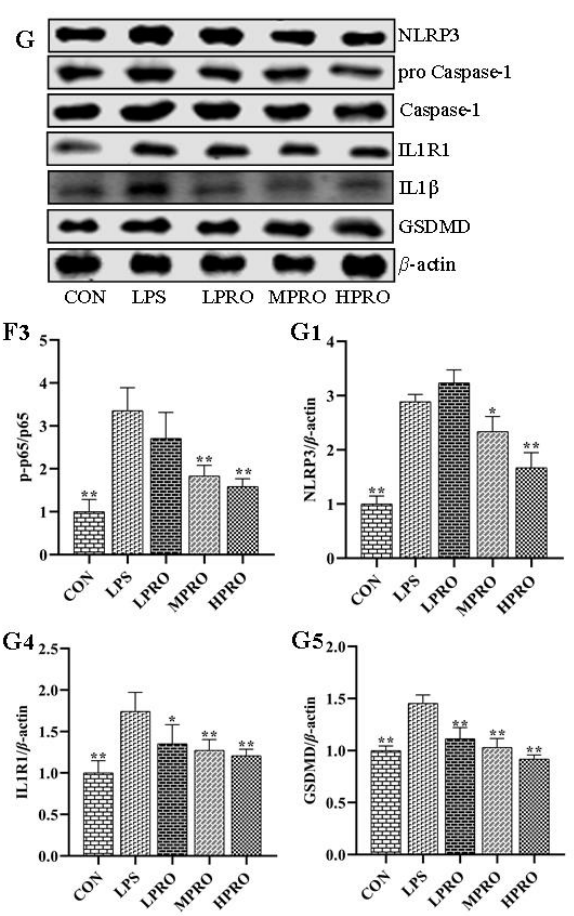

Figure 4. Effects of protopine on inflammatory response in mice with LPS-induced AKI $(n=8$ mice per group). (A) Effects of protopine on inflammation accumulation in mice with LPS-induced AKI detected by small animal imaging. (B-E) Effects of protopine on inflammatory cytokines in mice with LPS-induced AKI. (F,G) Effects of protopine on TLR4 signaling pathway in mice with LPS-induced AKI. ${ }^{*} p<0.05,{ }^{* *} p<0.01$ compared with the LPS group. (CBA: cytometric bead array; LPRO: low-dose protopine; MPRO: medium-dose protopine; HPRO: high-dose protopine; LPS: lipopolysaccharide; AKI: acute kidney injury; IL-2: interleukin-2; IFN- $\gamma$ : interferon- $\gamma$; IL-10: interleukin-10; TLR4: toll-like receptor 4; NLRP3: nod receptor heat protein domain associated protein 3; IL-1 $\beta$ : interleukin-1 $\beta$; IL1R1: interleukin-1 receptor 1; GSDMD: gasdermin; MyD88: myeloiddifferentiationfactor88).

The effect of protopine on LPS-induced inflammatory response was further explored by examining the levels of a number of proteins related to inflammation. As shown in Figure 4, protopine significantly inhibited the activation of the TLR4/MyD88/NF-KB pathway and reduced the levels of NLRP3, GSDMD, caspase-1/pro caspase-1, and IL1R1 in the kidney of mice with AKI.

\subsection{Effects of Protopine on the White Blood Cell Subtype in Peripheral Blood of Mice with LPS-Induced AKI}

The effects of protopine on the numbers of neutrophils and macrophages in peripheral blood were examined. The results (Figure 5) showed that the numbers of granulocytes, neutrophils, and macrophages significantly increased in peripheral blood of mice with LPS-induced AKI, which could be reversed by protopine effectively. 

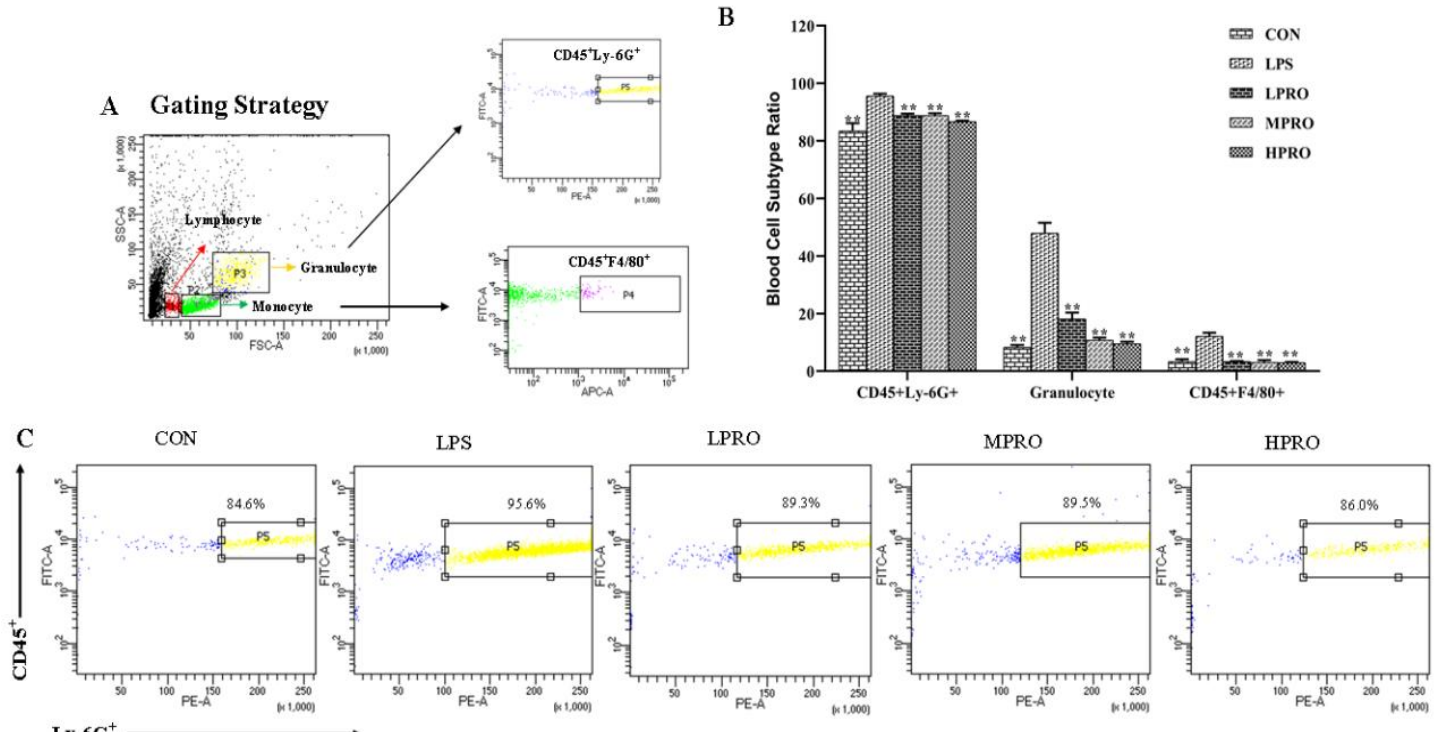
Ly- $6 \mathrm{G}^{+}$
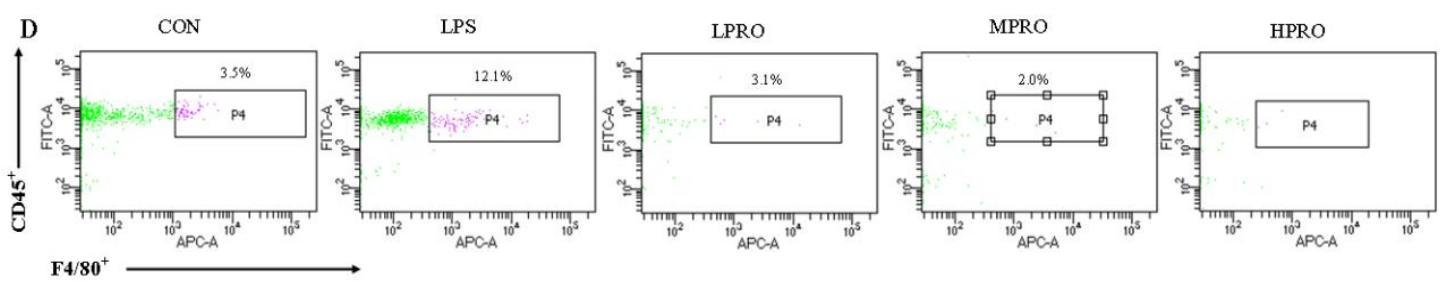

Figure 5. Effects of protopine on the blood cell subtype in mice with LPS-induced AKI ( $n=8$ mice per group). (A) Gating Strategy. (B) Effects of protopine on the blood cell subtype ratio in mice with LPS-induced AKI. (C,D) Effects of protopine on the ratio of $\mathrm{CD}_{4} 5^{+} \mathrm{Ly}-6 \mathrm{G}^{+}$and $\mathrm{CD} 45^{+} \mathrm{F} 4 / 80^{+}$in mice with LPS-induced AKI. ${ }^{*} p<0.05,{ }^{* *} p<0.01$ compared with the LPS group. (LPRO: low-dose protopine; MPRO: medium-dose protopine; HPRO: high-dose protopine; LPS: lipopolysaccharide; AKI: acute kidney injury).

\section{Discussion}

AKI is a grievous complication followed by sepsis, which could lead to high mortality [3]. A number of studies about AKI were focused on pathophysiological mechanisms and risk factors. However, the therapy of AKI and the causing mortality is still a challenging trouble in clinical practice [3]. C. humosa Migo is a traditional Chinese medicine that clears away damp heat, relieves sores, promotes blood circulation, and relieves pain. protopine is a compound isolated from C. humosa Migo, which has been reported to have various biological and pharmacological activities; however, the effect of protopine on AKI is not fully understood and needs to be further explored. This study found that protopine has a good protective effect on LPS-induced acute kidney injury in mice for the first time, and explored its possible mechanism of action, which could provide some new information about the use of protopine for treating AKI.

AKI is one of the complications of sepsis, and AKI is followed by a rapid decline in renal function [20]. The renal functions of all groups were evaluated by assessing the levels of BUN and Scr and observing renal histopathological sections stained with H\&E in mice with LPS-induced AKI. The mice injected with $5 \mathrm{mg} / \mathrm{kg}$ LPS suffered from severe renal pathological damage, including glomerular atrophy, tubular cell vacuolation, tubular dilation and distortion, tubular cell necrosis, and nuclear loss, accompanied by increase in the levels of Scr and BUN. However, these LPS-induced pathological changes were significantly attenuated by protopine, which could also reduce the levels of Scr and BUN in mice with AKI. Therefore, it was preliminarily concluded that protopine had a protective effect on the renal function of animals with LPS-induced AKI. 
As we all know, LPS is a crucial exogenous mediator of sepsis, which could give rise to metabolic disorder and organ failure by generating ROS [21] and mitochondria dysfunction. The short-dated outburst of ROS could lead to increased mitochondrial membrane permeability, reduced membrane potential, and release of apoptosis-inducing factors to give impetus to apoptosis. The production of ROS leads to changes in the expression of Bax and Bcl-2 and the activation of caspase- 3 and caspase-9. Apoptosis has recently been defined as a critical role of cell death, and studied suggest that the suppression of cell apoptosis could elevate survival in animal models of sepsis [22]. Moreover, our present study confirmed the inhibition effect of protopine on apoptosis induced by LPS. The results of this study showed that protopine could decrease the level of ROS in primary renal cells of mice with AKI, upregulate the level of Bcl-2, and downregulate the levels of Bax, cleaved caspase-3, and cleaved caspase-9. Our study indicates that protopine could inhibit LPS-induced apoptosis.

Studies have shown that sepsis induced AKI is accompanied by destruction of the immune system [23], and unconscionable apoptosis of immune cells can exacerbate sepsis and increase the mortality rate of patients. A grave inflammatory response induced by LPS stimulates neutrophils to emancipate numerous of pro-inflammatory cytokines, which have been reported to play pivotal roles in the pathogenesis of AKI [24]. In AKI, multiple inflammatory mediators are involved in organ damage. Pro-inflammatory cytokines, such as TNF- $\alpha$, IFN- $\gamma$, and caspase- 1 have been shown to accelerate the progression of LPS-induced AKI [25]. Moreover, the present study indicated that the numbers of granulocytes, neutrophils, and macrophages in peripheral blood significantly increased in mice with LPS-induced AKI, which could be reduced by protopine effectively. In addition, protopine could mitigate inflammation accumulation in mice induced by LPS. The levels of TNF, IFN- $\gamma$, and IL-2 elevated significantly in serum in LPS-induced mice, which could be reversed by protopine. Interestingly, the results showed that LPS increased the low levels of IL-10 in control mice. When the body is infected, such as AKI, the level of anti-inflammatory factor IL-10 in serum increases, but it is not enough to resist the injury. protopine could significantly increase the level of anti-inflammatory factor IL-10 in the serum of mice with AKI, thereby enhancing the body's ability to resist damage.

Toll-like receptor 4 (TLR4) is a classical pathogen recognition receptor of LPS, which plays a critical role in the innate immune system [6,26]. Upon stimulation with LPS, TLR4 can activate myeloid differentiation factor 88 (MyD88) and nuclear factor kappa-B (NF- $\kappa B$ ) [27]. TLR4 is activated by pathogen-associated factors, which could activate the NF- $\mathrm{KB}$ signaling pathway and sponsor the generation of pro-inflammatory cytokines and chemoattractants $[28,29]$. The transcription factor NF- $k B$ is a vital element in the inflammatory response, the activated NF- $\mathrm{kB}$ is transferred to the nucleus and induce the transcription of target genes, including pro-inflammatory cytokines, in tubular cells and infiltrated immune cells [30]. However, the emancipated inflammatory factor can also activate NF- $\mathrm{kB}$ pathway, forming a malicious cycle [31]. Moreover, the present study showed that the levels of TLR4, MyD88, and p-p65 significantly increased in mice induced by LPS, which were reduced by protopine.

Certain microbial components or some endogenous molecules including IL- $1 \beta$ and TNF- $\alpha$ can intervene NLRP3 deliverance through NF- $\mathrm{KB}$ p65 produced by TLRs. NLRP3, as a type of inflammasome, which has been reported to activate caspase-1, resulting in the generation of IL-1 $\beta$ [32]. Studies showed that NLRP3 inflammasome accelerate renal inflammatory response by generating inflammatory cytokines and NLRP3 inflammasome knockout mice were protected against kidney injury [33]. After the activation of NLRP3, proteins were oligomerized and tricked through homotypic molecular interactions, adaptor protein apoptosis-associated speck-like protein containing a caspase recruitment domain (ASC), and protease caspase-1 to form the inflammasome [34]. The formation of the inflammasome could lead to the activation of caspase-1, causing the processing of cellular substrates, including the cytokines pro-IL-1 $\beta$ and pro-IL-18 [35]. Interleukin-1 receptor (IL1R) is the receptor of IL- $1 \alpha$ and IL-1 $\beta$. As we all know, the proliferation and differentiation of immune cells, accelerated by IL- $1 \beta$, causes chemotaxis and agglutination to inflammatory cells, and precipitates the importation of activated immune cells into inflammatory sites. Caspase- 1 is the first discovered 
IL-1 $\beta$-converting enzyme, which is known as a primary player in inflammation and cell death. Caspase-1 is activated in NLRP3, which is a multiprotein oligomer composed of a certain intracellular pattern recognition receptor, adaptor ASC, and pro-caspase-1 [36]. Recently, gasdermin D (GSDMD) was identified as a determinant mediator of pyroptosis. Active caspase-1, caspase-4, caspase-5, and caspase-11 cleave GSDMD within a linker between its $\mathrm{N}$-terminal and C-terminal domains $[37,38]$. In addition, GSDMD could induce the release of IL-1 $\beta$. The present study found that the levels of NLRP3, caspase-1/pro-caspase-1, IL1R1, IL-1 $\beta$, and GSDMD increased in kidneys of mice with AKI, which could be reduced by protopine. Our study indicates that protopine could inhibit LPS-induced inflammatory response and activation of the TLR4 signaling pathway.

\section{Materials and Methods}

\subsection{General Experimental Procedure}

Nuclear magnetic resonance (NMR) spectroscopy was performed at room temperature using a Bruker Avance III $500 \mathrm{MHz}$ spectrometer with tetramethylsilane (TMS) as a standard. P-HPLC was acquired on the YMC-Pack ODS-A column $\left(250 \times 10 \mathrm{~mm}^{2}\right.$ and $\left.5 \mu \mathrm{m}\right)$ using Saipuruisi LC-50 instrument with a UV200 detector. CC was performed on Diaion HP-20 absorbent (Mitsubishi Chemical Co. Tokyo, Japan) and alumina column, and TLC was performed on custom silica gel G plates (Qingdao Marine Chemical Industry, Qingdao, China). The chemical reagents used for isolation were of analytical grade, and the solvents used for $\mathrm{p}$-HPLC were of chromatographic grade.

\subsection{Plant Materials}

The tubers of C. humosa Migo were collected from the Xinzheng ancestral mountain in Henan Province, China. The plant material was identified by Professor Suiqing Chen and Chengming Dong (Henan University of Chinese Medicine). The voucher number (No.20171026) of C. humosa Migo was deposited in the Research Department of Natural Medicinal Chemistry, School of Pharmacy, Henan University of Chinese Medicine.

\subsection{Extraction and Isolation}

The tubers of C. humosa Migo. (35 kg) were extracted by tissue fragmentation method with $70 \%$ acetone three times, concentrated and evaporated, and then dissolved in water with water-soluble substances $(320 \mathrm{~g})$. The water-soluble substances were resolved on a Diaion HP-20 macroporous resin column and successively eluted with $\mathrm{MeOH}-\mathrm{H} 2 \mathrm{O}(0: 100,20: 80$, and 40:60) to obtain three fractions (F1-F3). F3 (37.2 g) was suspended in $\mathrm{MeOH}$ and chromatographed on an alumina column eluted with $\mathrm{CH} 2 \mathrm{Cl} 2-\mathrm{MeOH}$ (80:1-1:1). The alumina column was purified by repeated column chromatography and combined with preparative liquid-phase recrystallization method to obtain the compound named LDD-16 (20 mg).

\subsection{LPS-Induced AKI In Vivo}

The study was conducted in accordance with the regulations for experimental animal management promulgated by the National Science and Technology Commission of the People's Republic of China. In this experiment (the license number for animal experiment: SYXK2015-0005), male BALB/c mice $(20 \pm 2 \mathrm{~g}, n=75)$ were purchased from Beijing Vital River Laboratory Animal Technology Co., Ltd. (SCXK2016-0006). They were adapted to the environment for a week and provided regular food and water every day. The mice were randomly divided into five groups ( $n=15$ per group) as follows: control $(\mathrm{CON}), \mathrm{LPS}(5 \mathrm{mg} / \mathrm{kg}), \mathrm{LPRO}+$ LPS (low-dose protopine, $10 \mathrm{mg} / \mathrm{kg}$ ), MPRO + LPS (medium-dose protopine $20 \mathrm{mg} / \mathrm{kg}$ ), and HPRO + LPS (high-dose protopine $30 \mathrm{mg} / \mathrm{kg}$ ). All mice were injected intraperitoneally with LPS, except those in the normal group that were injected intraperitoneally with saline. After $3 \mathrm{~h}$, different doses of protopine were administered intragastrically. The CON and LPS were given distilled water at the same time by gavage twice a day for 3 days. After $1 \mathrm{~h}$ of the last 
administration, inflammation accumulation was assessed by small animal living imaging. And after $24 \mathrm{~h}$ of the last administration, blood was extracted from their eyeballs, and the kidneys were carefully removed immediately and stored in the liquid nitrogen. The blood was centrifuged at $3000 \mathrm{rpm}$ for $10 \mathrm{~min}$ to obtain the supernatant. The blood and the kidney samples were stored at $-80{ }^{\circ} \mathrm{C}$ for further analysis.

\subsection{Flow Cytometry Analysis of White Blood Cell Subtype}

Whole blood anticoagulated with heparin sodium $(100 \mu \mathrm{L})$ was conjugated with fluoresceine isothiocyanate (FITC) rat anti-Mouse CD45 (553080, BD, USA), phycoerythrin (PE) rat anti-mouse Ly-6G and Ly-6C (553128), and Alexa Fluor 647 rat anti-mouse F4/80 (565853, BD) at room temperature for $30 \mathrm{~min}$. Then, $2 \mathrm{~mL}$ of $1 \times$ red cell lysate was added for $10 \mathrm{~min}$ at room temperature in the dark and centrifuged for $5 \mathrm{~min}$ at $300 \times \mathrm{g}$. The supernatant was discarded, and $2 \mathrm{~mL}$ of phosphate-buffered saline (PBS) was added for resuspension and centrifuged at $300 \times g$ for $5 \mathrm{~min}$. The supernatant was discarded again, and $500 \mu \mathrm{L}$ of PBS was added, followed by analysis by flow cytometry (FCM; FACS Aria III, San Jose, CA, USA).

\subsection{Primary Kidney Cells and Analysis of ROS}

Fresh kidney tissue (10 mg) was taken, chopped to a size of about $0.5 \mathrm{~mm}^{3}$, washed twice with PBS, and then resuspended in $0.25 \%$ trypsin digestion. Fetal bovine serum was used to stop digestion. The tissue was rinsed with PBS, filtered with 70- $\mu \mathrm{m}$ cell sieve, and centrifuged to obtain primary kidney cells. The resulting cells were used to detect the level of ROS by FCM using the commercially available kit (CA1410, Beijing Solarbio Science \&Technology Co., Ltd., Beijing, China) according to the manufacturer's recommendation. Briefly, the cells were collected and incubated with $10 \mu \mathrm{M}$ $2^{\prime}, 7^{\prime}$-dichlorofuorescein (DCFH-DA) for $20 \mathrm{~min}$ at $37^{\circ} \mathrm{C}$ in the dark. At the end of the incubation, the cells were washed with PBS three times to remove the free DCFH-DA molecules. All assays were performed in triplicate.

\subsection{Cytometric Bead Array Assay}

The contents of IL-10 (Mouse IL-10 Flex Set, 558300, BD), IFN- $\gamma$ (Mouse IFN- $\gamma$ Flex Set, 558296, BD), TNF (Mouse TNF Flex Set, 558299, BD), and IL-2 (Mouse IL-2 Flex Set, 558297, BD) in the serum of mice were detected using CBA according to the manufacturer's protocols. Initially, the different concentrations of standard products were formulated according to the respective preparations, and a standard curve was plotted. Then, $50 \mu \mathrm{L}$ of serum and $50 \mu \mathrm{L}$ of microspheres were mixed and incubated at room temperature in the dark for $2 \mathrm{~h}$. Then, $50 \mu \mathrm{L}$ of PE antibody conjugated with TNF, IL-2, IL-1 $\beta$, and IFN- $\gamma$ was added and incubated for $1 \mathrm{~h}$ at room temperature in the dark. Further, $1 \mathrm{~mL}$ of washing solution was added and centrifuged, and the supernatant was gently discarded. The resulting suspension was resuspended in $400 \mu \mathrm{L}$ of the buffer, and finally, the cytokine levels were measured by FCM, and the results were analyzed using the Diva (BD).

\subsection{Assessments of Biochemical Parameters}

The levels of BUN (C013-2, Nanjing Jiancheng Bioengineering Institute, Nanjing, Jiangsu, China) and Scr (C011-2, Nanjing Jiancheng Bioengineering Institute) in the serum of mice were detected using specific kits according to the manufacturer's instructions. All assays were performed in triplicate.

\subsection{Histomorphological Examination}

The kidneys were fixed in freshly prepared $4 \%$ paraformaldehyde and embedded. Each paraffin-embedded sample was cut into 5- $\mu$ m-thick sections and stained with hematoxylin and eosin. The images were viewed and acquired using a microscope (Nikon, Tokyo, Japan). 


\subsection{Western Blot Analysis}

Total protein was extracted from the renal tissue according to the instructions of the mammalian protein extraction kit (Beijing Com Win Biotech Co., Ltd., Beijing, China) and quantified using the Bradford protein assay kit (Wuhan Boster Biological Technology., Ltd., Wuhan, Hubei, China). Protein $(60 \mu \mathrm{g})$ was loaded per sample and separated using the SDS-PAGE gel. Then, non-fat milk was used to block the membrane for $1.5 \mathrm{~h}$, and the following primary antibodies were added: Bcl-2 (ab59348, Abcam, MA, USA), Bax (ab59348, Abcam), Caspase-3 (ab13847, Abcam), Caspase-9 (ab32539, Abcam), NF-kB p65 (ab16502, Abcam), NF-kB p-p65 (ab56299, Abcam), TLR4 (ab22048, Abcam), NLRP3 (ab4207, Abcam), IL1R1 (ab106278, Abcam), IL-1ß (ab9722, Abcam), GSDMD (ab209845, AbcamS), MyD88 (ab135693, Abcam), Caspase-1 (ab1872, Abcam), pro-Caspase-1 + p10 + p12 (ab179515, Abcam), and $\beta$-actin (ab8227, Abcam), incubated overnight at $4{ }^{\circ} \mathrm{C}$, and washed five times with PBST for 5 min each. Then, secondary antibodies (goat anti-rabbit 925-68071 and goat anti-mouse 925-32210, Li-COR, MO, USA) were added, incubated for $1 \mathrm{~h}$ in the dark, and washed four times with PBST for 5 min each time and finally with PBS. The expression of the proteins was quantified by Odyssey (CLx, Li-COR, Biosciences, Lincoln, NE, USA).

\subsection{Statistical Analysis}

Data were analyzed using the SPSS 20.0 software (IBM; Armonk, NY, USA). Statistical significance was assessed in comparison with the respective control for each experiment using one-way analysis of variance. A $p$ value less than 0.05 indicated a statistically significant difference.

\section{Conclusions}

In summary, the present study for the first time indicated that protopine isolated from C. humosa Migo protected mice against LPS-induced AKI by inhibiting apoptosis and inflammation, which might be related to the inhibition of TLR4 signaling pathway after the mice treated with protopine, thus providing a molecular basis for a novel medical treatment of AKI.

Author Contributions: B.Z. and M.Z. designed and performed the experiments and analyzed the raw data. M.L. provided protopine, Y.K., B.L., R.X., Y.W. and S.W. assisted with the experiments. X.Z. and W.F. supervised the project. All authors have read and agreed to the published version of the manuscript.

Funding: This research received no external funding.

Acknowledgments: This work was supported by the Central Government Guide Local Science and Technology Development Funds (14104349) and the Major Science and Technology Projects in Henan Province (171100310500).

Conflicts of Interest: The authors declare no conflict of interest.

\section{Abbreviations}

$\begin{array}{ll}\text { C. humosa Migo } & \text { Corydalis humosa Migo } \\ \text { PRO } & \text { protopine } \\ \text { LPS } & \text { lipopolysaccharide } \\ \text { AKI } & \text { acute kidney injury } \\ \text { BUN } & \text { blood urea nitrogen } \\ \text { Scr } & \text { serum creatinine } \\ \text { TNF } & \text { tumor necrosis factor } \\ \text { IL-2 } & \text { interleukin-2 } \\ \text { IFN- } \gamma & \text { interferon- } \gamma \\ \text { IL-10 } & \text { interleukin-10 } \\ \text { ROS } & \text { reactive oxygen species } \\ \text { TLR4 } & \text { toll-like receptor 4 } \\ \text { NLRP3 } & \text { nod receptor heat protein domain associated protein } 3\end{array}$




$\begin{array}{ll}\text { NMR } & \text { nuclear magnetic resonance } \\ \text { TMS } & \text { tetramethylsilane } \\ \text { DMSO } & \text { dimethyl sulfoxide } \\ \text { FITC } & \text { fluoresceine isothiocyanate } \\ \text { H\&E } & \text { hematoxylin and eosin } \\ \text { Bax } & \text { associated X protein } \\ \text { Bcl-2 } & \text { B-cell lymphoma } 2 \\ \text { CBA } & \text { cytometric bead array } \\ \text { IL-1 } \beta & \text { interleukin-1 } \beta \\ \text { IL1R1 } & \text { interleukin-1 receptor 1 } \\ \text { GSDMD } & \text { gasdermin } \\ \text { MyD88 } & \text { myeloiddifferentiationfactor88 }\end{array}$

\section{References}

1. Quoilin, C.; Mouithys-Mickalad, A.; Lecart, S.; Fontaine-Aupart, M.-P.; Hoebeke, M. Evidence of oxidative stress and mitochondrial respiratory chain dysfunction in an in vitro model of sepsis-induced kidney injury. Biochim. Et Biophys. Acta (BBA) - Bioenerg. 2014, 1837, 1790-1800. [CrossRef]

2. Bilgili, B.; Haliloglu, M.; Cinel, I. Sepsis and Acute Kidney Injury. Turk. J. Anesth. Reanim. 2014, 42, $294-301$. [CrossRef]

3. Robert, S.W.; Wang, W. Acute renal failure and sepsis. N. Engl. J. Med. 2004, 351, 159-169.

4. Zarjou, A.; Agarwal, A. Sepsis and acute kidney injury. J. Am. Soc. Nephrol. 2011, 22, 999-1006. [CrossRef] [PubMed]

5. Choudhary, G.S.; Al-Harbi, S.; Almasan, A. Caspase-3 activation is a critical determinant of genotoxic stress-induced apoptosis. Methods Mol. Biol. 2015, 1219, 1-9. [PubMed]

6. Nair, A.R.; Masson, G.S.; Ebenezer, P.J.; Del Piero, F.; Francis, J. Role of TLR4 in lipopolysaccharide-induced acute kidney injury: Protection by blueberry. Free. Radic. Biol. Med. 2014, 71, 16-25. [CrossRef] [PubMed]

7. Rosenthal, M.D.; Moore, F.A. Persistent Inflammation, Immunosuppression, and Catabolism: Evolution of Multiple Organ Dysfunction. Surg. Infect. 2016, 17, 167-172. [CrossRef]

8. Mariappan, N.; Soorappan, R.N.; Haque, M.; Sriramula, S.; Francis, J. TNF- $\alpha$-induced mitochondrial oxidative stress and cardiac dysfunction: Restoration by superoxide dismutase mimetic Tempol. Am. J. Physiol. Circ. Physiol. 2007, 293, H2726-H2737. [CrossRef]

9. Elks, C.M.; Mariappan, N.; Haque, M.; Guggilam, A.; Majid, D.S.; Francis, J. Chronic NF-kappaB blockade reduces cytosolic and mitochondrial oxidative stress and attenuates renal injury and hypertension in SHR. Am. J. Physiol. Ren. Physiol. 2009, 296, F298-F305. [CrossRef]

10. Abogresha, N.M.; Greish, S.M.; Abdelaziz, E.Z.; Khalil, W.F. Remote effect of kidney ischemia-reperfusion injury on pancreas: Role of oxidative stress and mitochondrial apoptosis. Arch. Med. Sci. 2016, 12, 252-262. [CrossRef]

11. Li, J.; Gui, Y.; Ren, J.; Liu, X.; Feng, Y.; Zeng, Z.; He, W.; Yang, J.; Dai, C. Metformin Protects Against Cisplatin-Induced Tubular Cell Apoptosis and Acute Kidney Injury via AMPK $\alpha$-regulated Autophagy Induction. Sci. Rep. 2016, 6, 23975. [CrossRef] [PubMed]

12. Renz, H.; Herzum, I. Inflammatory markers in SIRS, sepsis and septic shock. Curr. Med. Chem. 2008, 15, 581-587. [CrossRef] [PubMed]

13. Zhang, X.; Wang, C.; Shan, S.; Liu, X.; Jiang, Z.; Ren, T. TLR4/ROS/miRNA-21 pathway underlies lipopolysaccharide instructed primary tumor outgrowth in lung cancer patients. Oncotarget 2016, 7, 42172-42182. [CrossRef] [PubMed]

14. Tao, J.H.; Zhang, X.Q.; Ye, W.C.; Zhao, S.X. Chemical Constituents from Corydalis humsoa. Chin. Herb. Med. 2005, 28, 556-557.

15. Liu, C.; Zhao, S.X. Chemical constituents of Corydalis Humosa. J. China Pharm. Univ. 1989, 20, $261-265$.

16. Alam, M.B.; Ju, M.-K.; Kwon, Y.-G.; Lee, S.H. Protopine attenuates inflammation stimulated by carrageenan and LPS via the MAPK/NF-kB pathway. Food Chem. Toxicol. 2019, 131, 110583. [CrossRef] 
17. Wang, G.-X.; Zhou, Z.; Jiang, D.-X.; Han, J.; Wang, J.-F.; Zhao, L.-W.; Li, J. In vivo anthelmintic activity of five alkaloids from Macleaya microcarpa (Maxim) Fedde against Dactylogyrus intermedius in Carassius auratus. Vet. Parasitol. 2010, 171, 305-313. [CrossRef]

18. Kosina, P.; Gregorova, J.; Gruz, J.; Vacek, J.; Kolar, M.; Vogel, M.; Roos, W.; Naumann, K.; Simanek, V.; Ulrichova, J. Phytochemical and antimicrobial characterization of Macleaya cordata herb. Fitoterapia 2010, 81, 1006-1012. [CrossRef]

19. Rathi, A.; Srivastava, A.K.; Shirwaikar, A.; Rawat, A.K.S.; Mehrotra, S. Hepatoprotective potential of Fumaria indica Pugsley whole plant extracts, fractions and an isolated alkaloid protopine. Phytomedicine 2008, 15, 470-477. [CrossRef]

20. Yamada, T.; Ishikawa, S.; Kataoka, S.; Uda, T.; Iinuma, Y.; Hattori, R.; Yamada, T.; Morikawa, M.; Kaneuchi, M.; Minakami, H. Coagulation/Fibrinolysis and laboratory characteristics of pregnant women with severely depressed antithrombin activity. Hypertens. Pregnancy 2013, 32, 235-244. [CrossRef]

21. Aksu, U.; Ergin, B.; Bezemer, R.; Kandil, A.; Milstein, D.M.J.; Demirci-Tansel, C.; Ince, C. Scavenging reactive oxygen species using tempol in the acute phase of renal ischemia/reperfusion and its effects on kidney oxygenation and nitric oxide levels. Intensiv. Care Med. Exp. 2015, 3, 57. [CrossRef] [PubMed]

22. Harjai, M.; Bogra, J.; Kohli, M.; Pant, A.B. Is suppression of apoptosis a new therapeutic target in sepsis. Anaesth Intensive Care 2013, 41, 175-183. [CrossRef] [PubMed]

23. Uchida, T.; Ito, S.; Kumagai, H.; Oda, T.; Nakashima, H.; Seki, S. Roles of Natural Killer T Cells and Natural Killer Cells in Kidney Injury. Int. J. Mol. Sci. 2019, 20, 2487. [CrossRef]

24. Mortensen, J.; Shames, B.; Johnson, C.P.; Nilakantan, V. MnTMPyP, a superoxide dismutase/catalase mimetic, decreases inflammatory indices in ischemic acute kidney injury. Inflamm Res. 2011, 60, 299-307. [CrossRef]

25. Cunningham, P.N.; Dyanov, H.M.; Park, P.; Wang, J.; Newell, K.A.; Quigg, R.J. Acute renal failure in endotoxemia is caused by TNF acting directly on TNF receptor-1 in kidney. J. Immunol. 2002, 168, 5817-5823. [CrossRef]

26. Mian, M.O.R.; He, Y.; Bertagnolli, M.; Mai-Vo, T.A.; Fernandes, R.O.; Boudreau, F.; Cloutier, A.; Luu, T.M.; Nuyt, A.M. TLR (Toll-Like Receptor) 4 Antagonism Prevents Left Ventricular Hypertrophy and Dysfunction Caused by Neonatal Hyperoxia Exposure in Rats. Hypertension 2019, 74, 843-853. [CrossRef]

27. Jia, S.-J.; Niu, P.-P.; Cong, J.-Z.; Zhang, B.-K.; Zhao, M. TLR4 signaling: A potential therapeutic target in ischemic coronary artery disease. Int. Immunopharmacol. 2014, 23, 54-59. [CrossRef]

28. Teo, J.D.; Macary, P.A.; Tan, K.S. Pleiotropic effects of Blastocystis spp. Subtypes 4 and 7 on ligand-specific toll-like receptor signaling and NF-kappaB activation in a human monocyte cell line. PLoS ONE 2014, 9, e89036. [CrossRef]

29. Zhang, K.; Jiao, X.F.; Li, J.X.; Wang, X.W. Rhein inhibits lipopolysaccharide-induced intestinal injury during sepsis by blocking the toll-like receptor 4 nuclear factor-kappaB pathway. Mol. Med. Rep. 2015, 12, 4415-4421. [CrossRef]

30. Alvero, A.B. Recent insights into the role of NF-kappaB in ovarian carcinogenesis. Genome Med. 2010, 2, 56. [CrossRef]

31. Benzer, F.; Kandemir, F.M.; Kucukler, S.; Comaklı, S.; Caglayan, C. Chemoprotective effects of curcumin on doxorubicin-induced nephrotoxicity in wistar rats: By modulating inflammatory cytokines, apoptosis, oxidative stress and oxidative DNA damage. Arch. Physiol. Biochem. 2018, 124, 1-10. [CrossRef]

32. Tschopp, J.; Schroder, K. NLRP3 inflammasome activation: The convergence of multiple signalling pathways on ROS production? Nat. Rev. Immunol. 2010, 10, 210-215. [CrossRef]

33. Vilaysane, A.; Chun, J.; Seamone, M.E.; Wang, W.; Chin, R.; Hirota, S.; Li, Y.; Clark, S.A.; Tschopp, J.; Trpkov, K.; et al. The NLRP3 inflammasome promotes renal inflammation and contributes to CKD. J. Am. Soc. Nephrol. 2010, 21, 1732-1744. [CrossRef]

34. Martinon, F.; Mayor, A.; Tschopp, J. The Inflammasomes: Guardians of the Body. Annu. Rev. Immunol. 2009, 27, 229-265. [CrossRef]

35. Laetitie, A.; Fabio, M.; Kimberly, B.; Michael, F.M.; Philip, N.H.; Jurg, T. NALP3 Forms an IL-1 $\beta$-Processing Inflammasome with Increased Activity in Muckle-Wells Autoinflammatory Disorder. Immunity 2004, 20, 319-325.

36. Kohsuke, T.; Hideki, H. The Inflammasome and Its Regulation. Crit. Rev. Immunol. 2014, 34, 41-80.

37. Shi, J.; Zhao, Y.; Wang, K.; Shi, X.; Wang, Y.; Huang, H.; Zhuang, Y.; Cai, T.; Wang, F.; Shao, F. Cleavage of GSDMD by inflammatory caspases determines pyroptotic cell death. Nature 2015, 526, 660-665. [CrossRef] 
38. Kayagaki, N.; Stowe, I.B.; Lee, B.L.; O’Rourke, K.; Anderson, K.; Warming, S.; Cuellar, T.; Haley, B.; Roose-Girma, M.; Phung, Q.T.; et al. Caspase-11 cleaves gasdermin D for non-canonical inflammasome signalling. Nature 2015, 526, 666-671. [CrossRef]

Sample Availability: Not available.

(C) 2019 by the authors. Licensee MDPI, Basel, Switzerland. This article is an open access article distributed under the terms and conditions of the Creative Commons Attribution (CC BY) license (http://creativecommons.org/licenses/by/4.0/). 